\title{
Identification and evaluation of the volatile organic compounds in working environment areas at a material recycling facility
}

\author{
M. S. Elmegrahi, G. Karani \& K. Morris \\ Cardiff School of Health Sciences, University of Wales, Cardiff, UK
}

\begin{abstract}
Volatile organic compounds (VOCs) are major components of air pollution. It is well recognized that exposure to certain types of VOCs may cause occupational health effects such as respiratory disease, eye irritation, immune and neurological damage, and reproductive and endocrine disorders.

Different techniques are used to identify the VOC concentration that workers may be exposed to in the working environment. In this study, real-time monitoring of VOC was determined in August and September 2006 using a MiniRAE 2000 PID at a Material Recycling Facility (MRF) in Wales, UK. An inspection of the site was undertaken before the measurements were made to assist us determine the appropriate sampling locations, and to fully understand the operations at the MRF.

Benzene, Toluene, Ethyl benzene and Xylene (BTEX) were detected at different working environment areas at the MRF. Although the values monitored were low and are unlikely to have any primary health effects, it is worth investigating any unpleasant odours that may cause secondary symptoms Key words: air pollution, material recycling, emissions, VOCs
\end{abstract}

\section{Introduction}

Although several researchers have addressed the risk of waste facilities, for instance congenital anomalies and malignancies in relation to living in closeproximity to landfill sites, the health impacts of new waste management technologies and the increasing use of recycling and composting is an area that always require further assessment and monitoring Rushton [1], Megrahi et al. [2]. 
There are several initiatives in various parts of the world that encourages the public to recycle waste, which is usually taken to Material Recycling Facilities, MRF, to be sorted. The types of Material Recycling Facilities vary from MRFs that only bale source separated materials to Single Stream facilities that use appropriate sorting methods to prepare recovered materials for market.

No work that we have come across has been published on the levels of volatile organic compounds, VOCs, in a manual sorting MRF, and this paper provides data on levels determined at an MRF site in Wales, UK.

Although indoor VOCs have been found to cause asthma-like symptoms Norback et al. [3], there is little epidemiologic work on ambient exposures. There are no data on relationships between respiratory health and exhaled breath VOCs, which is a biomarker of VOC exposure. Pappas et al. [4] study concluded that reductions in levels of VOC to substantially less than $25 \mathrm{mg} / \mathrm{m}^{3}$ are required if a "non-irritating" work environment is desired. In regions of high traffic density, stronger associations for ambient than for breath VOCs have been determined suggesting that ambient VOC measurements are better markers for daily exposure to combustion-related compounds thought to be causally related to acute asthma Delfino et al. [5]. There is now evidence that VOCs play a role in exacerbating respiratory symptoms Beck et al. [6].

\section{Materials and methods}

The MRF site chosen for this study is located in Wales, UK, and waste materials delivered at the site are sorted manually. In a week, the MRF site receives 160 tonnes of domestic municipal waste and 660 tonnes of commercial waste. The waste is separated manually on a segregation line and then baled.

Before the measurements were taken, a pre-inspection survey was completed and the information gathered used during the walk-through the facility to assist the authors to be familiar with the operations at the MRF.

Real-time monitoring of VOC was determined using a MiniRAE 2000 PID. Monitoring was determined on four periods during an 8-hour working shift - four in August and one in September 2006. The levels were monitored at the beginning, middle-point and the end of the sorting line.

The PID was selected because of the portability, size, ease of use and data logging capabilities. The PID was calibrated using isobutylene. Air was drawn through the PID at $450 \mathrm{ml} / \mathrm{min}$. The PID was equipped with a $10.6 \mathrm{ev}$ lamp and measurements taken every second. All data were stored in non-volatile memory, and later downloaded to a computer and analysed. The MiniRae PID provides the most cost-effective detailed exposure assessment for solvent mixtures Coy et al. [7], and it has been used to monitor organic compounds Walsh et al. [8], Simpson et al. [9], Preller et al. [10], Enomoto [11]. The response of the portable PID used to monitor VOC has been found to highly correlate to the standard charcoal sorbent tubes, analyzed by gas chromatography, results for hydrocarbon mixtures encountered during various painting tasks Coy et al. [7] The MiniRae PID is compliant with the specifications contained in EPA Method 21 (40FR) for leak detection and monitoring of fugitive emissions. 


\section{Results and discussion}

The results from the survey identified the common VOCs to be Benzene, Toluene, Ethyl benzene and Xylene (BTEX), Table 1.

Table 1: Average BTEX levels in ppm on the sorting line at the MRF.

\begin{tabular}{|l|c|c|c|}
\hline & Beginning & Middle & End \\
\hline Benzene & 0.29 & 0.40 & 0.21 \\
\hline & & & \\
\hline Toluene & 0.27 & 0.39 & 0.2 \\
\hline & & & \\
\hline Ethyl benzene & 0.28 & 0.39 & 0.20 \\
\hline & & & 0.18 \\
\hline Xylene & 0.25 & 0.57 & \\
\hline & & & \\
\hline
\end{tabular}

The levels of BTEX determined at the beginning of the segregation line in August and September 2006 are shown in Figures 1 and 2, while the variation of benzene at the end of the segregation line is shown in Figure 3. The contribution to the BTEX values at the 3 sampling points is shown in Figure 4.

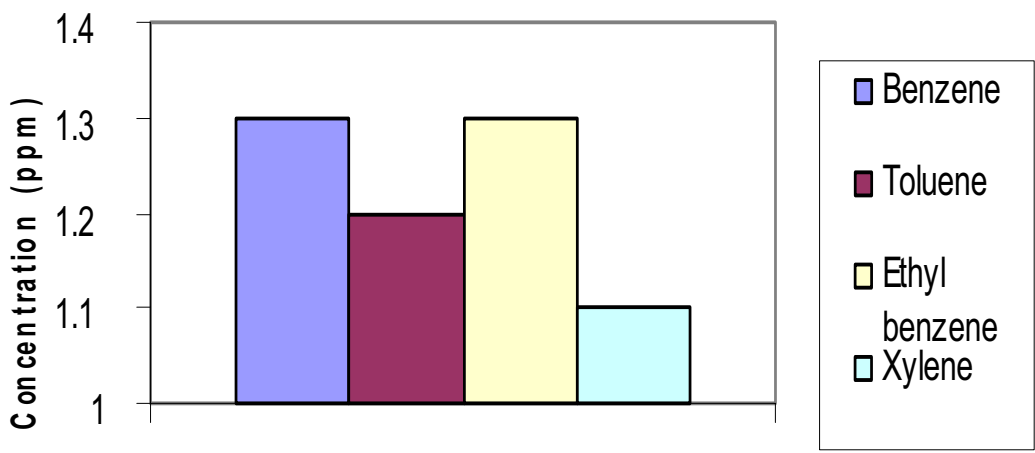

Figure 1: Average VOCs at the beginning of segregation area 4 August 2006.

The BTEX average values observed at the MRF are low. However measurements made during the first monitoring period on 4 August 2006, were $1.3,1.2,1.3$ and $1.1 \mathrm{ppm}$ for benzene, toluene, ethyl benzene and xylene respectively. The corresponding measurements during the other periods were notably lower as the MRF had reduced the delivery of organic waste. In addition, there were marked improvements in working conditions including increased ventilation and the regular cleaning of the sorting line and the surrounding areas. From the walk-about survey, we had pointed out these measures to the MRF operator, and were delighted that their implementation resulted in a huge 
reduction in BTEX concentration. The other areas we suggested changes were on site operation, and in the welfare and further training of the employees.

The VOCs, at these low concentrations have not been reported to have any primary health effects, but it is worthy investigating any unpleasant odours that may cause secondary symptoms such as nausea and hypersensitivity reactions normally reported in other types of waste facilities Muller et al. [12] and Tolvanen et al. [13]

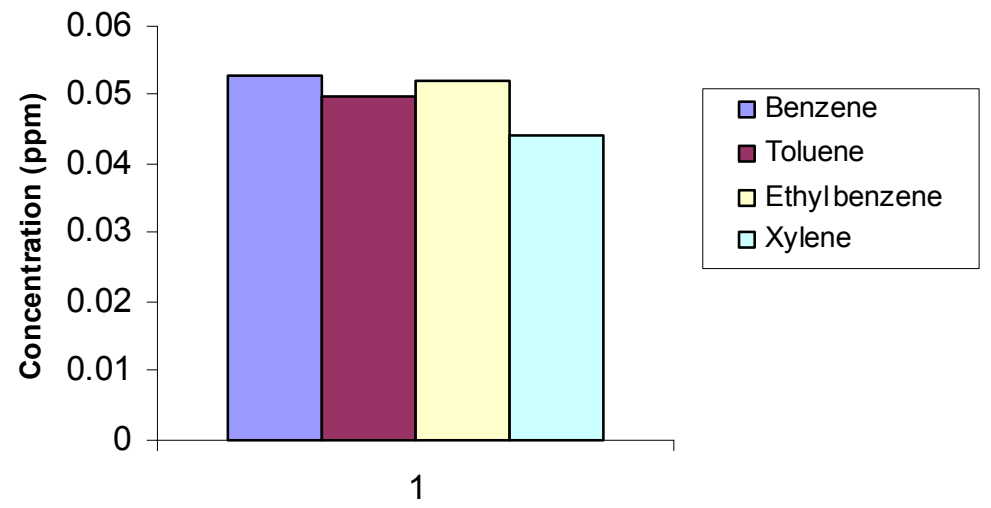

Figure 2: Average VOCs at the beginning of segregation area in September 2006.

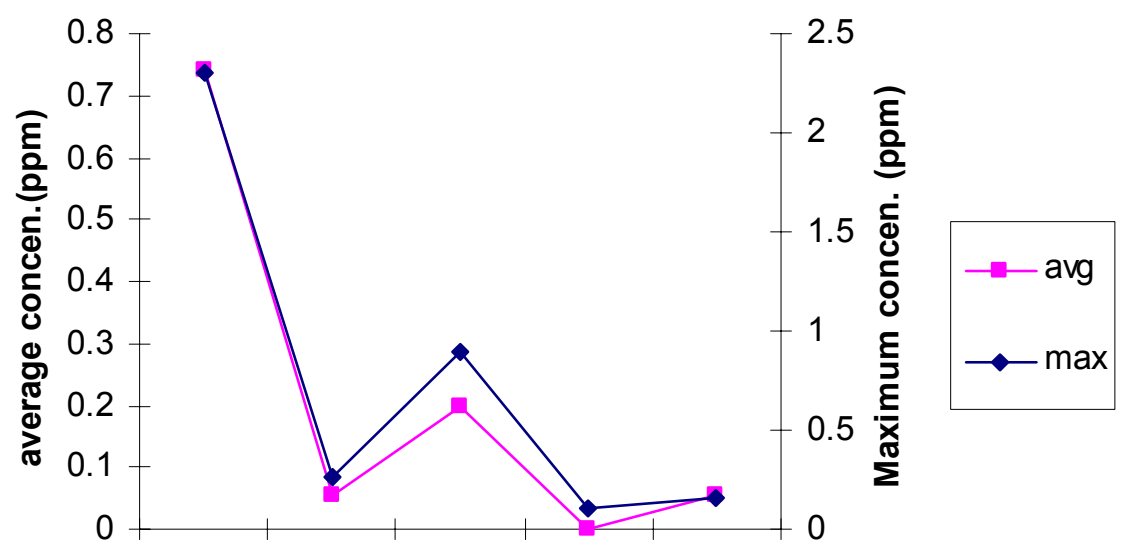

04Aug. 10Aug. 11Aug. 23Aug. 08Sept.

Figure 3: Variation of benzene at the end of segregation line. 


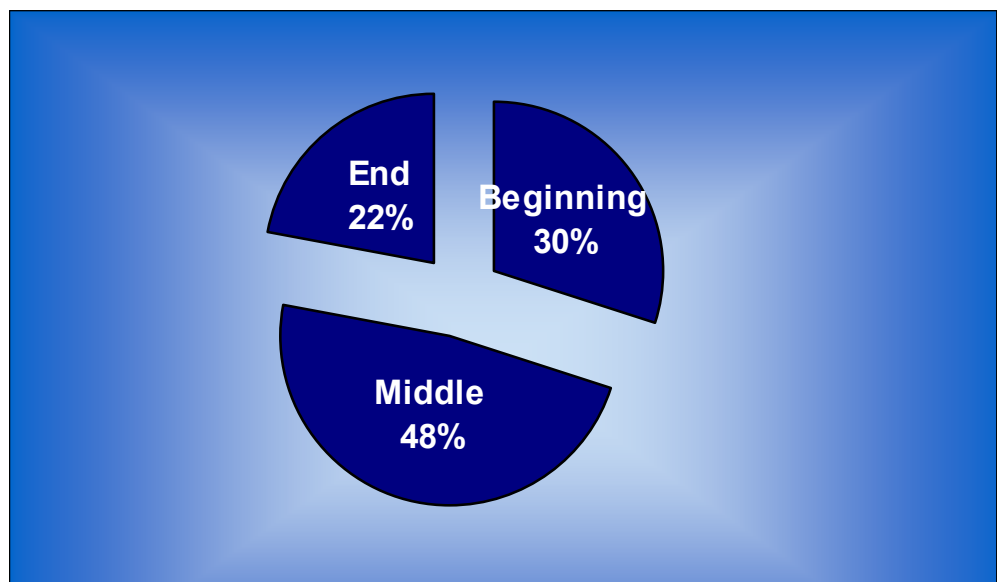

Figure 4: BTEX concentration in the 3 stages of the segregation line.

\section{Conclusions}

The data collected at the MRF shows that the PID is a useful tool for real time VOC measurement. Although the VOC concentrations were low, further improvement on the site that has taken place since September 2006 will continue to help improve the working environment at the site.

The paper has demonstrated how simple remedial measures in an MRF can reduce the pollutant levels that workers are exposed to.

\section{References}

[1] Rushton L. Health hazards and waste management. Br Med Bull. 68, pp 183-97, 2003

[2] Megrahi M S, Karani George, Morris Keith. chemical hazard exposure as result of waste land filling, a review, Waste Management and the Environment III ed . Popov, V, et al, 367-374., 2006

[3] Norback D, Bjornsson E, Janson C, Widstrom and Boman G Asthmatic symptoms and volatile organic compounds, formaldehyde, and carbon dioxide in dwellings Occup Environ Med, 52, 388-395, 1995

[4] Pappas, GP, Herbert RJ, Henderson, W, Koenig, J, Stover B and Barnhard $\mathrm{S}$. The respiratory effects of volatile organic compounds, Int $\mathrm{J}$ Occup Environ Health, 6, 1-8, 2000

[5] Delfino RJ, Gong H, Linn WS, Hu Y and Pellizzari ED. Respiratory symptoms and peak expiratory flow in children with asthma in relation to volatile organic compounds in exhaled breath and ambient air $J$ Expo Anal Environ Epidemiol, 13,348-363, 2003 
[6] Beck, JP, Heutelbeck A and Dunkelberg H. Volatile organic compounds in dwelling houses and stables of dairy and cattle farms in Northern Germany. Sci Total Enviro 20, 31, 2006

[7] Coy JD, Bigelow PL, Buchan, RM, Tessari JD and Parnell JO. Field evaluation of a portable photo ionization detector for assessing exposure to solvent mixtures, AIHAJ, 61, 268-274., 2000

[8] Walsh PT, Clark RDR, Flaherty S and Plant IJ. Monitoring exposure to solvent vapour in the workplace using a video-visualization technique, Noise and Health, 4,1-7, 2002

[9] Simpson AT, Hardwick KR, Walsh PT, Brown RC and Hemmingway MA. Evaluation of diffusive samplers and photoionisation detectors for measuring very short peak exposures in the workplace, $J$ Environ Monit., 5, 732-738, 2003

[10] Preller L, Burstyn I, De Pater N and Kromhout N. Characteristics of peaks of inhalation exposure to organic solvents, Ann Occup Hyg, 48, 643652,2004

[11] Enomoto M. Evaluation of individual exposure to organic solvents using a portable VOC monitor. Sangyo Elseigaku Zashi, 48,214-220, 2006

[12] Muller, T, Thissen R, Braun S, Dott W and Fischer G. (M)VOC and composting facilities. Part 2: (M)VOC dispersal in the environment, Environ Sci .Pollut. Res. Int., 11, 162-157, 2004.

[13] Tolvanen O, Nykanen J, Nivukoski U, Himanen M, Velianen A and Hanninen K. Occupational Hygiene in a Finnish drum compositing plant, Waste Manag. 25, 427-433, 2005 